\title{
PYOGENIC ARTHRITIS, PYODERMA GANGRENOSUM AND ACNE (PAPA) SYNDROME - A RARE DIAGNOSIS
}

Carla Luchese de Almeida ${ }^{1,{ }^{*}}$, Kamilla de Bessa Jorge ${ }^{1}$, Laís Zanlorenzi ${ }^{1}$, Thelma Larocca Skare ${ }^{1}$

1. Hospital Evangélico Mackenzie de Curitiba, Curitiba (PR), Brazil.

${ }^{\star}$ Corresponding author: cah_luchese@hotmail.com

\section{BACKGROUND}

Pyogenic arthritis, pyoderma gangrenosum, and acne (PAPA) syndrome is a rare disease, that has been described in 1997. It is an autosomal-dominant disorder that causes oligoarticular, destructive arthritis, typically involving elbows, knees, and/or ankles. It is linked to mutations in the gene of proline-serine-threonine phosphatase interacting protein 1 (PSTPIP1) increasing its link to an inflammasome component, the pyrin restricting its anti-inflammatory activity.

\section{CASE REPORT}

A 28-year-old Caucasian male with history of juvenile idiopathic arthritis since age of 8 and severe acne since age of 15 was referred to our service for treatment. He had previous use of methotrexate, leflunomide and etanercept, but at referral was using only prednisone $20 \mathrm{mg} / \mathrm{day}$. He presented with a severe arthritis in left elbow and skin lesion of acne conglobata (Fig. 1). He was treated with antibiotics during one month (meropenem, vancomycin plus cephazolin) with initial diagnosis of septic arthritis but without help. Multiple skin open pyoderma-like lesions (Fig. 2) appeared and this suspicion was confirmed by biopsy. The diagnosis of PAPA syndrome was made and the patient received glucocorticoid, adalimumab plus cyclosporine with slow but progressive regression of arthritis and skin lesions (Fig. 3).

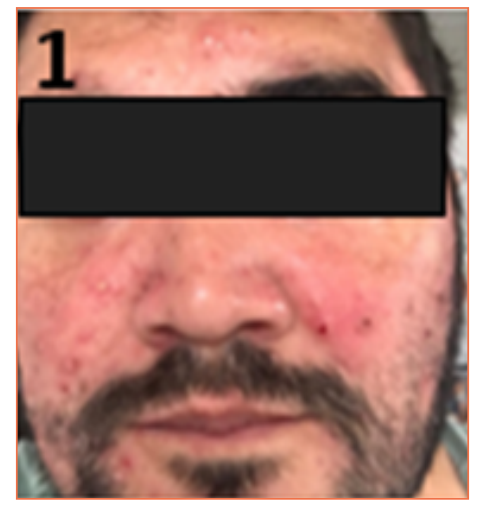

Figure 1. Skin lesion of acne conglobata.
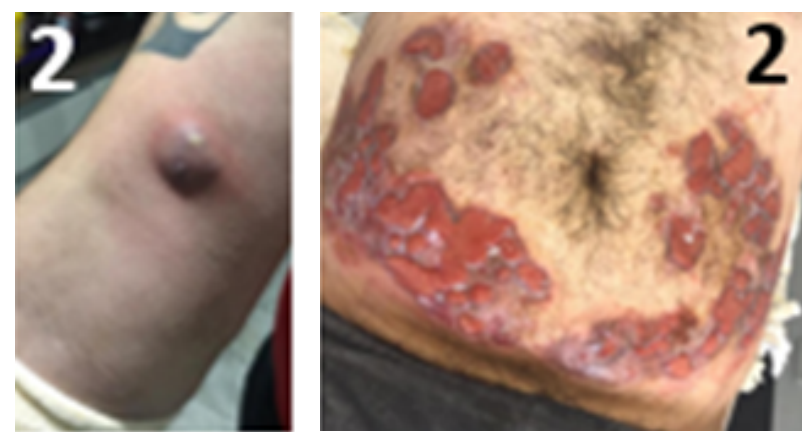

Figure 2. Multiple skin open pyoderma-like lesions. 


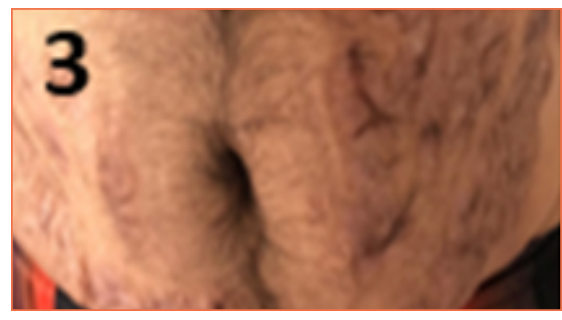

Figure 3. Progressive regression of arthritis and skin lesions.

\section{CONCLUSION}

Pyogenic arthritis, pyoderma gangrenosum, and acne syndrome is a rare condition that nowadays has good therapeutic options. Therefore, it is important to know this diagnosis in order to help these patients to avoid the destructive arthritis, pain in the pyodermalike lesions, recurrent infections favored by open wounds and to improve their quality of life. 